\title{
Finite Element Modelling and Updating of Welded Thin-Walled Beam
}

\author{
M. S. M. Fouzi ${ }^{1}$, K. M. Jelani ${ }^{1}$, N. A. Nazri ${ }^{1}$ and M. S. M. Sani ${ }^{1,2^{*}}$ \\ ${ }^{1}$ Advanced Structural Integrity and Vibration (ASIVR), \\ Faculty of Mechanical Engineering, Universiti Malaysia Pahang, \\ 26600 Pekan, Pahang, Malaysia \\ *Email: mshahrir@ump.edu.my \\ Phone: +6094246231; Fax: +6094246222 \\ ${ }^{2}$ Automotive Engineering Centre, Universiti Malaysia Pahang, \\ 26600 Pekan, Pahang, Malaysia
}

\begin{abstract}
This article concentrates on the finite element (FE) modelling approach to model welded thin-walled beam and the adoption of model updating technique to enhance the dynamic characteristic of the FE model. Four different types of element connectors which are RBE2, CBAR, CBEAM and CELAS format are used to construct the FE model of welded structure. Normal mode analysis is performed using finite element analysis (FEA) software, MSC Patran/Nastran to extract the modal parameters (natural frequency and mode shape) of the FE model. The precision of predicted modal parameters obtained from the four models of welded structure are compared with the measured counterparts. The dynamic characteristics of a measured counterpart is obtained through experimental modal analysis (EMA) using impact hammer method with roving accelerometer under free-free boundary conditions. In correlation process, the CBAR model has been selected for updating purposes due to its accuracy in prediction with measured counterparts and contains updating parameters compared to the others. Ahead of the updating process, sensitivity analysis is made to select the most sensitive parameter for updating purpose. Optimization algorithm in MSC Nastran is used in FE model updating process. As a result, the discrepancy between EMA and FEA is managed to be reduced. It shows the percentage of error for updated CBAR model shrinks from $7.85 \%$ to $2.07 \%$ when compared with measured counterpart. Hence, it is found that using FE model updating process provides an efficient and systemic way to perform a feasible FE model in replicating the real structure.
\end{abstract}

Keywords: finite element model; finite element analysis; experimental modal analysis; finite element model updating; sensitivity analysis.

\section{INTRODUCTION}

Performance and durability for each structure begins from the initial stage of its development. An engineer or designer will design the structure based on its application and through calculations without knowing the actual performance. In their article[1], it is stated that when doing response calculations in design, simulation of this type of nearresonant dynamic is very sensitive to even small variations in modal parameters (damping ratio, natural frequency and mode mass). Under those circumstances, knowing modal parameters of the test structure together with its mode shape as precisely as possible has become essential. With this intention, modal analysis is an effective method for analyzing 
the dynamic characteristics of the test structure to determine its performance and durability owing to vibration problems. Structural analysts are continuously challenged to produce better designs to fulfil the safety, economic and environmental regulations required by the authorities. Current research on modal analysis is focused on determining the dynamic behaviour of a test structure using experimental approaches via experimental modal analysis (EMA) and a numerical prediction technique using finite element analysis (FEA).

Several publications have appeared in recent years documenting the dynamic studies on vibration problems. One of the first examples of dynamic studies is presented by [2] to model friction stir welding (FSW) joint for vibration analysis. Another work regarding dynamic characteristics is in correlation with numerical and experimental analysis for dynamic behaviour of a body-in white (BIW) structure presented by [3]. Recently, there are quite a number of researches concerning dynamic behaviours of exhaust structures which have been discussed by [4-7]. Normally, an exhaust structure experiences dynamic load produced by an operational engine and uneven road conditions transferred via the hangers. Hence, to evaluate if the structure can stand with the operational and ambient frequency or not, the dynamic study of that particular structure is required.

However, to the authors' best knowledge, very limited publications have elaborated the joint modelling strategies to replicate the outstanding welded joint on exhaust structures. Hence, the main objective of this study was to identify the most reliable weld connector model; rigid body element Type2 (RBE2), bar element (CBAR), beam element (CBEAM) and spring element (CELAS) existed in MSC Nastran/Patran to represent the real welded joint on thin-walled beam structure. Due to the complexity of exhaust structures, only thin-walled beam was used as the test structure since it seemed to be as prominent as the main structure in an exhaust fabrication. In extension, this study also inspired by [2] in their research which reported the behaviour of FSW joints play a significant role in the dynamic characteristics of a structure due to its complexities and uncertainties. Therefore, the representation of an accurate FE model of the joint becomes a research issue.

A number of preliminary works have been done to model the weld joint on their test structures several years ago. For instance, [8] used CWELD elements for representing laser spot welds joints in a top-hat structure in their dynamic analysis based on FE modelling and updating technique. With the same intention, [9] attempted to construct an FE model of the laser spot welded structure using joint strategy; three different types of element connectors which are RBE2, ACM and CWELD ELPAT format were identified in their study. Therefore, the path illustrated by previous researchers in the study of dynamics is extended to this paper to model welded joint on thin-walled beam, differing from the earlier one using plate structure. To model and solve the vibration problems numerically, FEA method was adopted in this study since it has become the most favourable technique in parallel to the development of high computing capability paired with recent advances in numerical methods. As reported by [10], FEA was used in the industry to gain a confidence level in the early design stage, and to analyse the product performance, as well as to predict the dynamic characteristics of the structure definitely.

Since the modal parameters obtained from FEA are a numerical prediction, it has become a necessity to carry out the EMA to verify the predicted data obtained from the FE model. EMA has grown steadily in popularity since the advent of digital Fast Fourier Transform (FFT) spectrum analyzer in the early 1970's, and recently impact testing has become widespread as a fast and economical means of finding the modes of vibration of 
a structure [11]. Usually, there are two common methods implemented to excite the test structure in modal testing - shaker and impact hammer excitation. In spite of both methods, [12] stated that the impact hammer has been the preferred method of transient excitation for modal testing since it is fast, convenient, and very useful for quick diagnostics.

In order to verify either the constructed FE model is feasible to represent the actual dynamic behaviour produced by real structure or not, numerous researchers used correlation processes to compare the modal data obtained from FEA with measured counterparts[3, 9, 10, 13, 14].From the correlation processes, the level of discrepancy between prediction results and its experimental data were then calculated. The outstanding joint model among RBE2, CBAR, CBEAM and CELAS model with less error percentage was chosen to be treated with FE model updating. In this study, CBAR has been chosen for the updating process since it has showed the most precise result to replicate a real welded structure, and contained the most updated parameters compared to others joint models. Although RBE2 did not have updating parameters and displayed good correlation, it was still used in this study to represent the maximum response of FE model as a rigid body without any welded joint.

The cost of using high performance computers is expensive in predicting the overall response of a test structure. Instead of computational issues, the researchers normally reduced the details of the FE model by making certain assumptions and approximations, for instance by neglecting complex angles on the geometry model. Resulting from the simplifications made on the FE model led to discrepancies between predicted data and their measured counterparts. Hence, the FE model updating was used to reduce these discrepancies by modifying the modelling assumptions and parameters until the correlation between numerical predicted data and measured counterparts satisfied practical requirements [15]. Ahead of the updating process, it was necessary to execute sensitivity analysis to identify which were the most influential parameters to be chosen. As mentioned by[16], the parameters selected should be justified by engineering understanding of the structure, and the number of parameters should be kept to a minimum to avoid ill-conditioning problems. A number of published papers managed to reduce the discrepancies between predicted results of FEA and measured data from EMA using FE model updating with MSC Nastran optimization algorithm, SOL200 [2, 9, 10, $13,17]$.

This paper manages to establish the feasible model of welded thin-walled beam using finite element modelling and model updating through dynamic characteristics of the test structure. Welded joint has been successfully modelled with the joint strategy approach using existing element connector in the FEA package. The results and methods implied in this study can be extended to other complex structures such as exhaust structure, buggy car chassis, motorcycle frame and etc. which use thin-walled beam (or normally known as tube) as the main structure.

\section{FE MODELLING: THIN-WALLED BEAM AND WELDED JOINT}

\section{FE Modelling of Thin-Walled Beam}

With the purpose of predicting numerically the dynamic characteristics of the test structure in this study, FEA approach was adopted using FEA package MSC Nastran/Patran. The FE model of thin-walled beam such as displayed in Figure 1 is constructed and meshed with 497 shell elements with 293 nodes (CTRIA3 topology) and 
8 weld element connectors using joint strategy (RBE2, CBAR, CBEAM and CELAS element connectors) existing in MSC Nastran. The profile of FE model is set to be $38 \mathrm{~mm}$ for outer diameter and $1.3 \mathrm{~mm}$ of thickness. The total length of the constructed model is $1200 \mathrm{~mm}$, with a $3 \mathrm{~mm}$ gap in the middle as shown in Figure 1.

The nominal values of material properties assigned for the FE model are as follows; Young's Modulus $(E)$ is $190 \mathrm{GPa}$, density $(\rho)$ is $7850 \mathrm{~kg} / \mathrm{m}^{3}$ and Poisson's Ratio (v) is 0.265. Next, normal mode analysis SOL103 was executed to compute modal parameters of the FE model once the required setup was done including joint strategy. In this study, solution sequence SOL103 was adopted to simulate the free-free boundary conditions, which meant no load or translational and rotational boundary conditions were applied to any node on the structure [13]. The computed modal parameters were summarized in Table 1 for eigenvalue, and Table 2 for the eigenvector of the test structure. Details of this joint strategy were explained in "weld joint modelling strategy" section below.

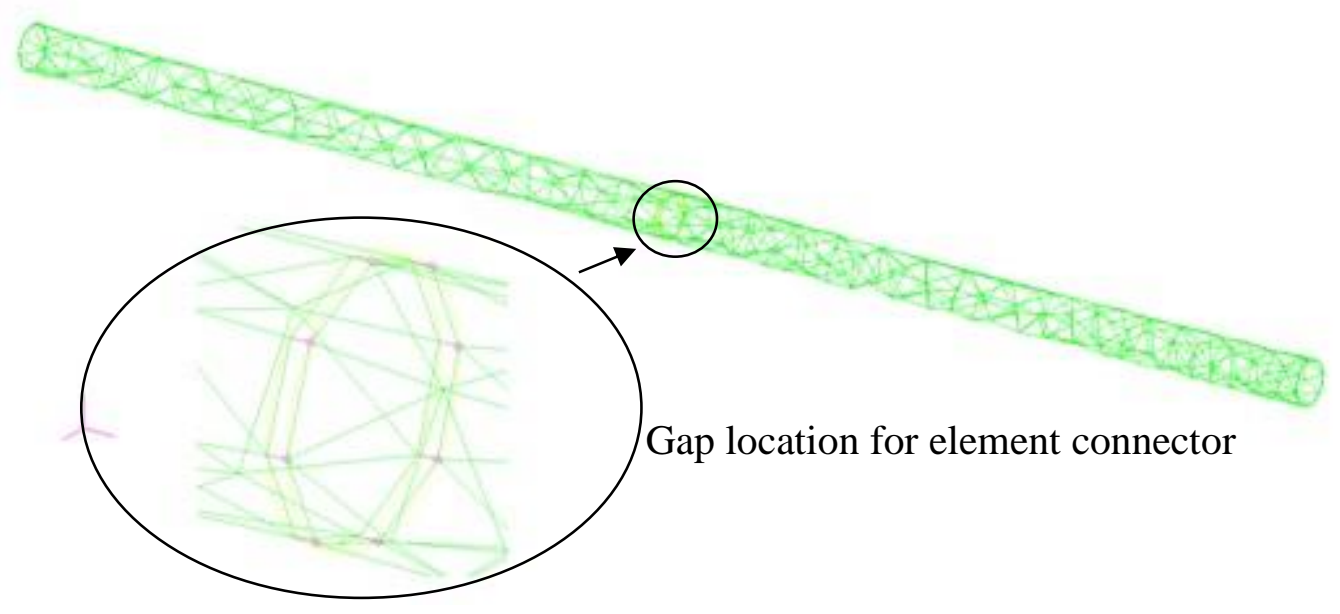

Figure 1. Thin-walled beam modelled in FEA.

\section{Weld Joint Modelling Strategy}

In representing the actual condition of a welded structure, the element connectors available in MSC Nastran/Patran were used in this study. The weld model illustration adopted in this research is in Figure 2(a) to (d) respectively; for rigid body type2 (RBE2) element connector, bar (CBAR) element connector, spring (CELAS) element connector and beam (CBEAM) element connector. These element connectors are assigned on the FE model to connect the two thin-walled beams at the gap location as depicted in Figure 1 .

The RBE2 element as shown in Figure 2(a) defined a rigid body whose independent degrees of freedom were specified at a single point, and whose dependent degrees of freedom (DOFs) were specified at an arbitrary number of points [18]. The RBE2 element used constraining equations to couple the motion of the dependent DOFs to the motion of the independent DOFs. Consequently, RBE2 elements did not contribute directly to the stiffness matrix of the structure, and ill-conditioning was avoided. The CBAR element as portrayed in Figure 2(b)was a general purpose beam that supported tension and compression, torsion, bending in two perpendicular planes, and shear in two perpendicular planes [18]. The CBAR used two grid points and provided stiffness to all 
six DOFs of each grid point. With CBAR, its elastic axis, and shear centre all coincided. The displacement components of the grid points were three translations and three rotations.

The CBEAM element as seen in Figure 2(d) provided all of the capabilities of the CBAR element, plus the following additional capabilities; i). The neutral axis and shear centre did not need to coincide, which were important for unsymmetrical sections, ii). The effect of cross-sectional warping on torsional stiffness was included (PBEAM only), iii). The effect of taper on transverse shear stiffness (shear relief) was included (PBEAM only) [18]. The CELAS in Figure 2(c) was defined as spring elements to connect two DOFs at two different grid points [18]. They behaved like simple extension/compression or rotational (e.g. clock) spring, carrying either force or moment loads. Forces resulted in translational (axial) displacement, and moments resulted in rotational displacement.

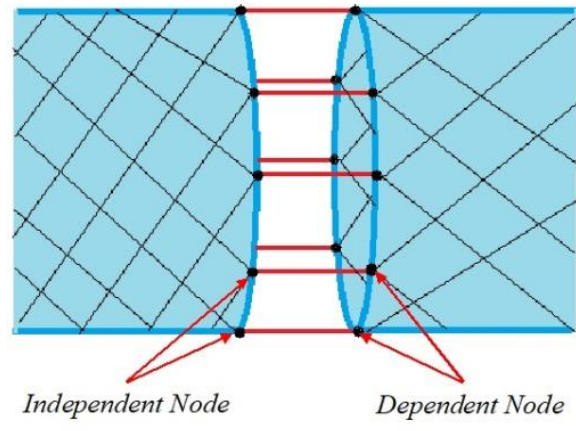

(a)

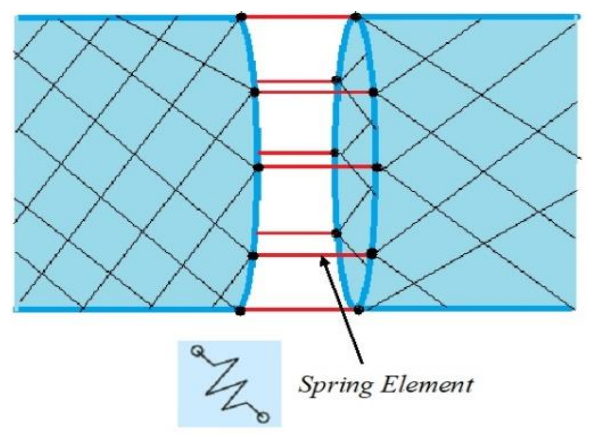

(c)

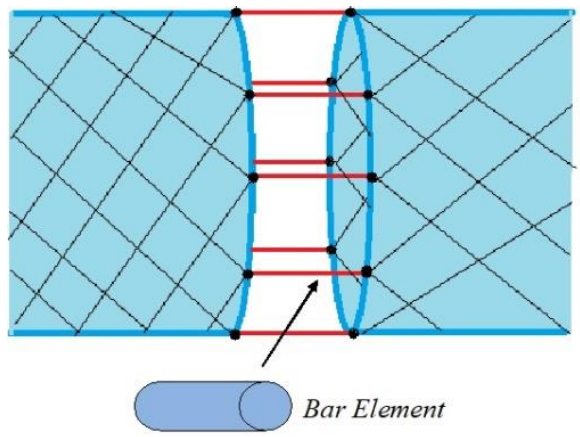

(b)

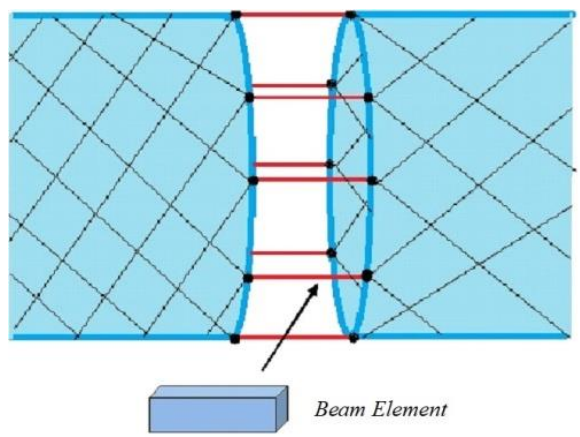

(d)

Figure 2. (a) RBE 2, (b) CBAR, (c) CELAS and; (d) CBEAM element connector.

\section{THIN-WALLED BEAM: EXPERIMENTAL PROCEDURES}

In order to acquire the dynamic behaviour of the test structure in this study, modal testing process was implemented using impact the hammer excitation technique. The test specimen was prepared as portrayed in Figure 3 using two simple stainless steel tubes which have been welded at the middle. The geometry of the test structure used is as follows; overall length is $1200 \mathrm{~mm}$, outer diameter is $38 \mathrm{~mm}$, and thickness is $1.3 \mathrm{~mm}$. The test structure was hanged on an elastic cord to represent free-free boundary condition.

The measurement process was carried out with the aid of EMA equipment as displayed in Figure 4. The measurement procedure in this study as illustrated in Figure 5used the roving accelerometer technique. In the preliminary stage of the testing, the test structure was labelled with 13 measurement points with one fixed excitation point, 
sketched in a wire-frame model in EMA software as seen in Figure 6. In this study, measurement point number 2 was declared as a fixed excitation point. Tri-axial accelerometer from National Instrument (NI) was used to measure the output response from the testing. Hence, there were 39 DOFs on the structure computed since each measurement points were measured of $\mathrm{x}, \mathrm{y}$, and $\mathrm{z}$ axes using tri-axial accelerometers.

The quality of data obtained in this study was influenced by the signal processing in the testing process. The force signal from the hammer was sensed by force transducer equipped at the hammer tip with the sensitivity of $2.25 \mathrm{mV} / \mathrm{g}$. The type of hammer tip used in this study was of medium type. The output response of the testing was measured using piezoelectric tri-axial accelerometer. The sensitivity of tri-axial accelerometer used in this study were; $102 \mathrm{mV} / \mathrm{g}$ for x-axis, $104 \mathrm{mV} / \mathrm{g}$ for $\mathrm{y}$-axis and $100 \mathrm{mV} / \mathrm{g}$ for $\mathrm{z}$-axis. Since the impact hammer technique had been used in this testing, the quality or consistency of excitation became an issue. From [19], the coherence function was used as a data quality assessment tool, which identified how much of the output signal was related to the measured input signal. Therefore, coherence graph seen in Figure 7was used to evaluate the quality of force given by operator to excite the test structure. The coherence could be shown to be always less than or equal to 1.0 [20]. In addition, the types of windowing used in this study to capture the signal was exponential since it was referred to by[19], which reported for impact excitation, the most common window used on the response transducer measurement was the exponentially decaying window.

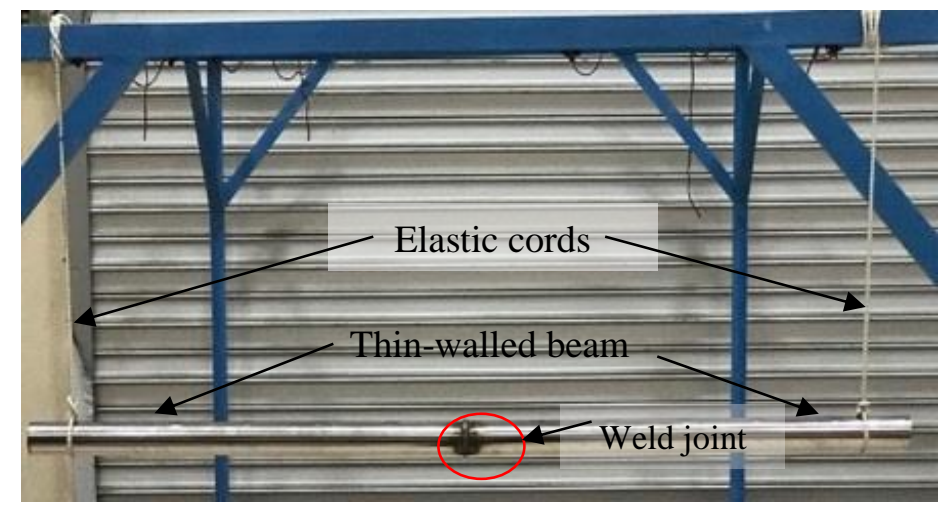

Figure 3. Prepared test structure (thin-walled beam).

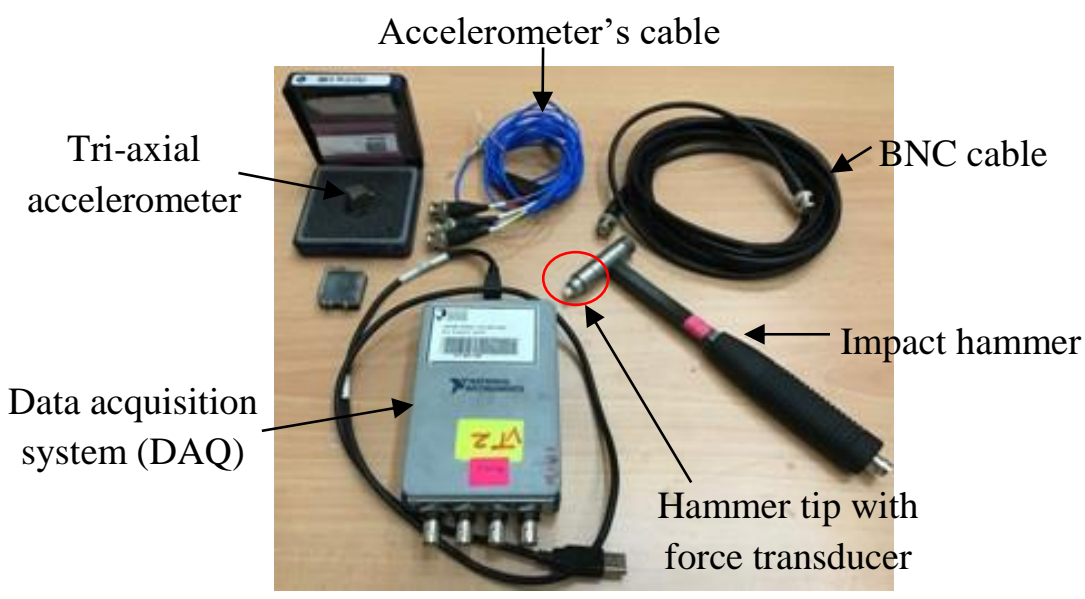

Figure 4.Required equipment in EMA. 
Both force and response signals were transferred to the data acquisition system (DAQ) in the form of FFT as illustrated in Figure 5, and then transformed into FRFs as seen in Figure 8 to be used for extracting the modal parameters. From the FRFs data, the curve fitting process was applied to extract the modal properties; natural frequency and mode shape from tested structure using modal testing software, ME's Scope VES. Resulting from the curve fitting process, there were 9 modes obtained in the frequency range of $1 \mathrm{~Hz}$ to $2000 \mathrm{~Hz}$ which had been set in the beginning of the measurement process. The measured natural frequencies for the 9 modes have been laid out in the row of EMA in Table 1, which had been used as benchmark values to validate the predicted result from FEA.

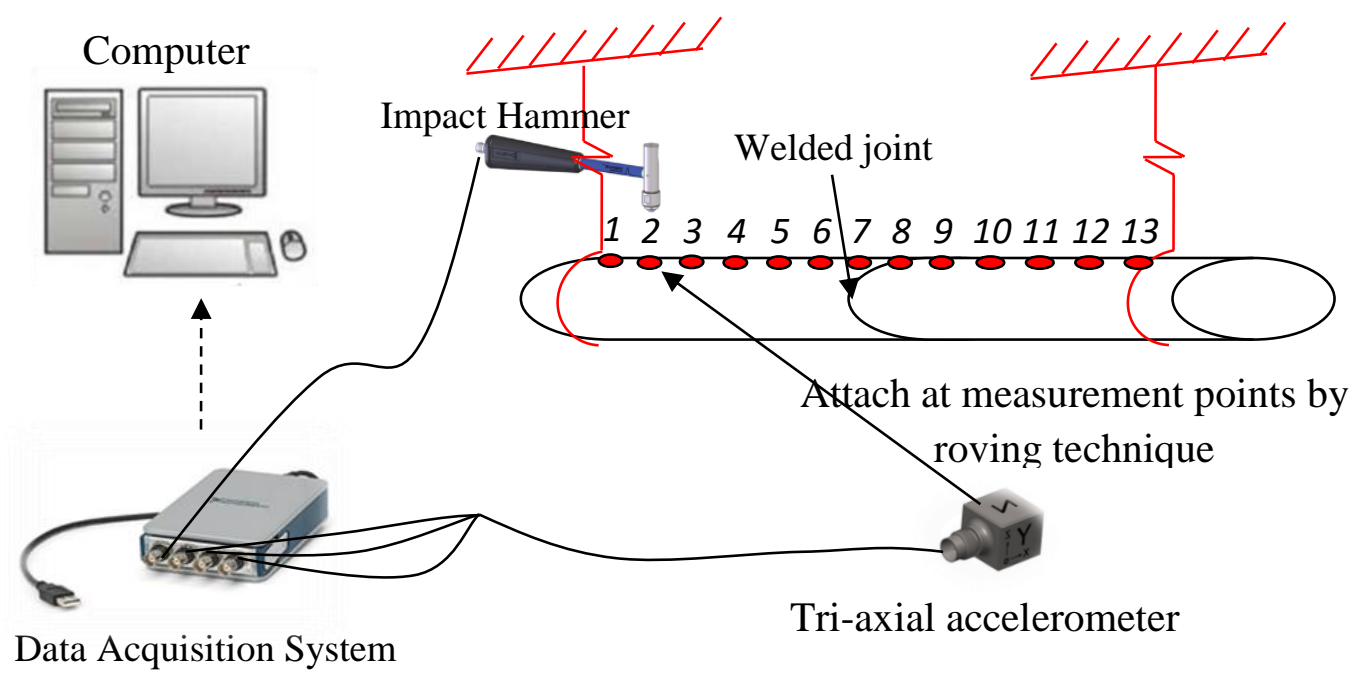

Figure5. Configuration used in modal testing.

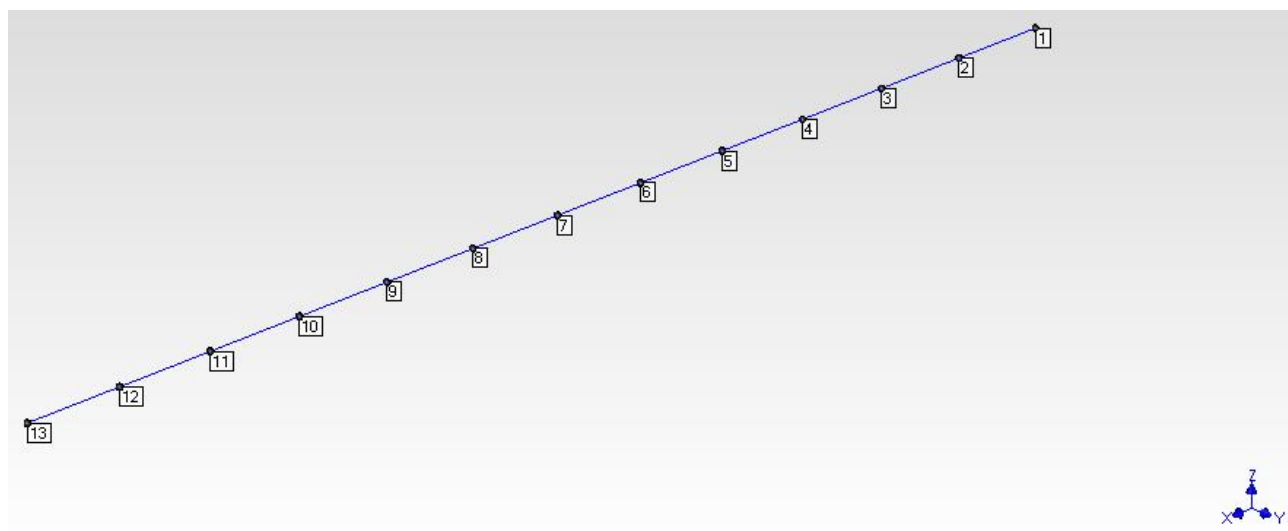

Figure 6. Wire-frame model sketched in EMA software. 


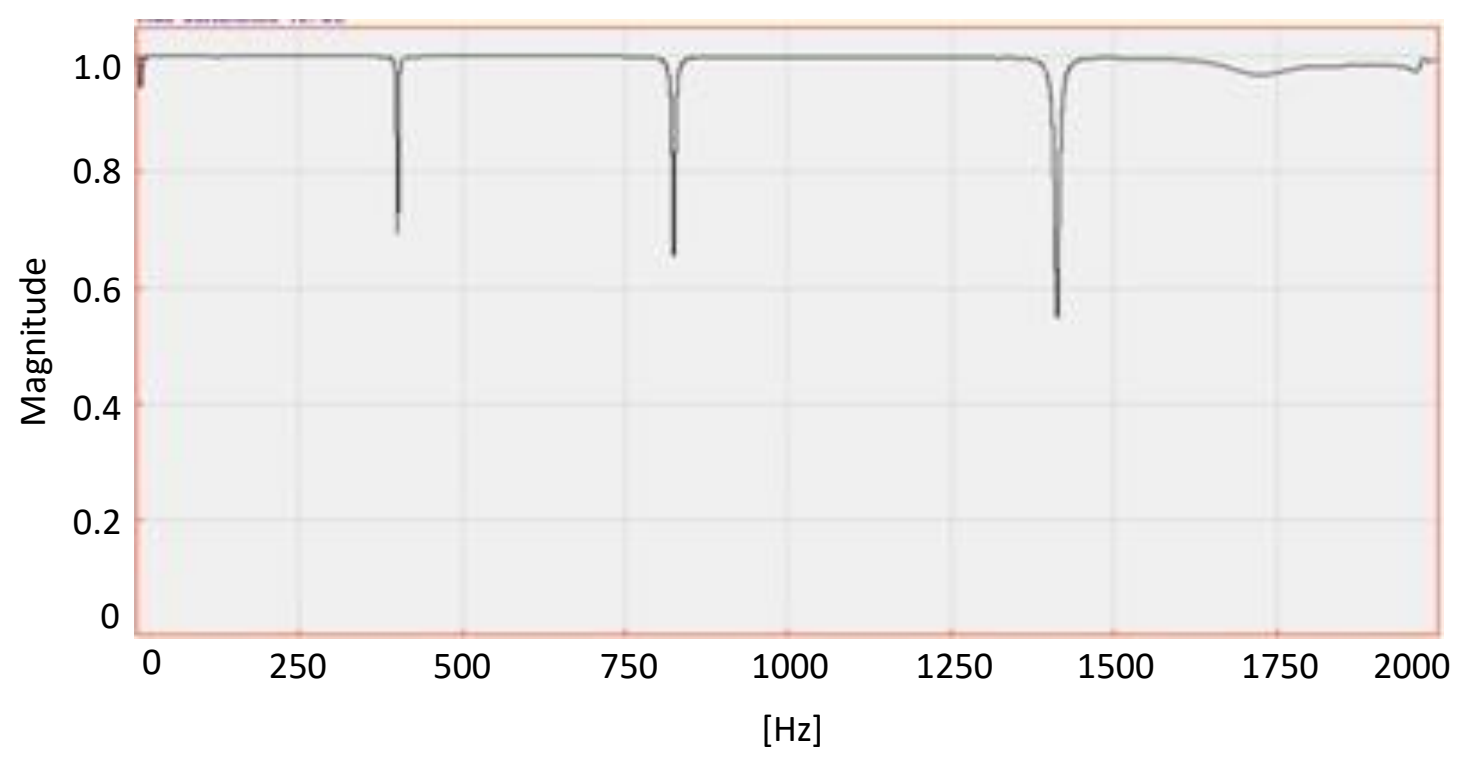

Figure 7. Coherence graph used to indicate the quality of excitation.

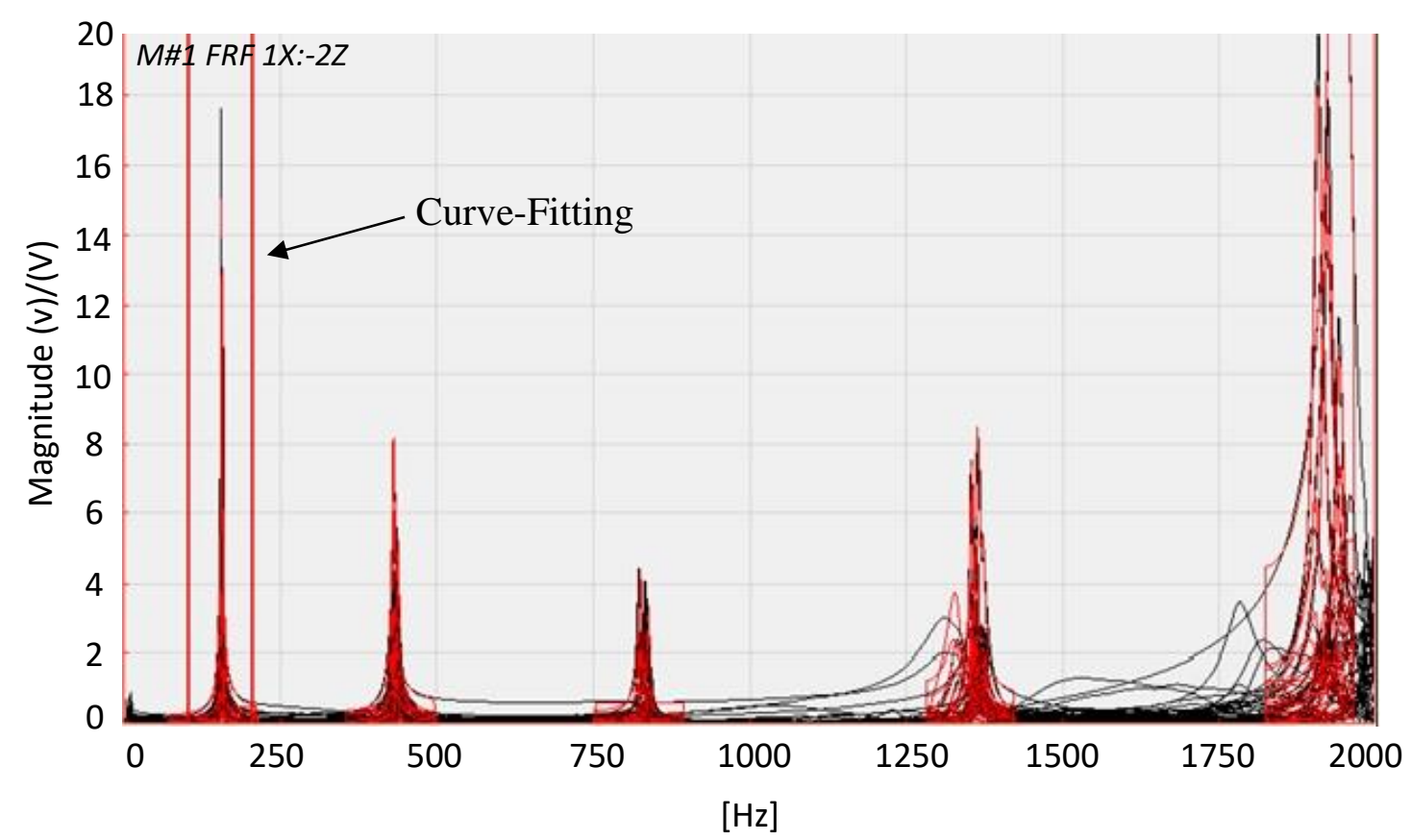

Figure 8. Overlay traces of FRFs executed from modal testing.

\section{CORRELATION BETWEEN FEA AND EMA}

In the process of choosing the most steadfast model to replicate weld joints, the four types of weld models were compared with the benchmark values obtained from EMA. As tabulated in Table 1, the percentage of error of RBE2 model, CBAR model, CBEAM model and CELAS model were compared to EMA and calculated. While in Table 2, the prediction of mode shapes (MS) of the thin-walled beam were computed from FE model with different element connectors. 
Table 1. Natural frequencies of FEA (joint strategy) correlate with EMA data.

\begin{tabular}{lccccccccc}
\hline \multirow{2}{*}{ Mode } & & \multicolumn{7}{c}{ Natural Frequency (Hz) } \\
& EMA & RBE2 & $(\%$ E) & CBAR & $(\%$ E) & CBEAM & $(\%$ E) & CELAS & $(\%$ E) \\
\hline 1 & 157 & 147.56 & 6.01 & 147.07 & 6.32 & 146.11 & 6.94 & 118.49 & 24.53 \\
2 & 159 & 150.86 & 5.12 & 150.33 & 5.45 & 149.34 & 6.08 & 119.98 & 24.54 \\
3 & 432 & 389.28 & 9.89 & 389.18 & 9.91 & 388.83 & 9.99 & 559.18 & 29.44 \\
4 & 439 & 396.49 & 9.68 & 396.41 & 9.70 & 396.10 & 9.77 & 578.29 & 31.73 \\
5 & 826 & 788.90 & 4.49 & 786.36 & 4.80 & 781.85 & 5.35 & 681.49 & 17.50 \\
6 & 839 & 822.47 & 1.97 & 819.90 & 2.28 & 815.34 & 2.82 & 711.43 & 15.21 \\
7 & 1360 & 1228.10 & 9.70 & 1227.40 & 9.75 & 1224.80 & 9.94 & 1475.40 & 8.49 \\
8 & 1370 & 1243.20 & 9.26 & 1242.40 & 9.31 & 1239.90 & 9.50 & 1565.00 & 14.23 \\
9 & 1910 & 1779.30 & 6.84 & 1773.90 & 7.13 & 1764.60 & 7.61 & 1594.90 & 16.50 \\
\multicolumn{2}{l}{ Total average error: } & 7.00 & & 7.18 & & 7.55 & & 20.24 \\
\hline
\end{tabular}

The resulting calculations explains that RBE2 model is the most outstanding weld model with the lowest percentage of error, followed by CBAR model and CBEAM model with slight differences. However, the CELAS model is found ill with a large percentage of error and is thus not taken into consideration for updating purpose. In addition, the predicted mode shape of the CELAS model seems unidentical compared to the other models for third and fourth mode referred in Table 2.

For model updating purpose, RBE2 model seems to be the best model to represent the weld joints. However, RBE2 model does not contain any geometrical and material properties that are proficient enough to be used in the updating process. Different situations with CBAR and CBEAM models possess appropriate parameters in weld modelling, and as such can be used for updating purpose. Instead of the slight differences in percentage of error between CBAR and CBEAM model, it is clear that the CBAR model is the more precise model in predicting the dynamic behaviour of real structures. Therefore, the CBAR model has been chosen for finite element model updating purpose to improve the correlation between numerical predictions of welded models with its measured counterparts.

\section{FE MODEL UPDATING}

In attempting to trim down the incongruity of numerical predicted results, FE model updating was implemented in this research using physical data from experimental counterparts. The summary of the overall process included in the updating process can be seen in Figure 9. The iterative methods using modal data has been used in this study with the adoption of SOL200 optimization algorithm supported by MSC Nastran.

\section{Sensitivity Analysis}

Put forward by previous researchers as mentioned in the introduction, the four parameters involved in this study (Young Modulus of stainless steel 304, density of stainless steel 304, Poisson's Ratio of stainless steel 304 and thickness of CBAR element connector) have been checked for being either sensitive or not for updating purposes. Careful parameterisation performed via sensitivity analysis is in the form of Eq. (1) [9].

$$
\mathbf{S}=\boldsymbol{\phi}_{i}^{\mathrm{T}}\left[\frac{\partial \mathbf{K}}{\partial \theta_{j}}-\lambda_{i} \frac{\partial \mathbf{M}}{\partial \theta_{j}}\right] \boldsymbol{\phi}_{i}
$$




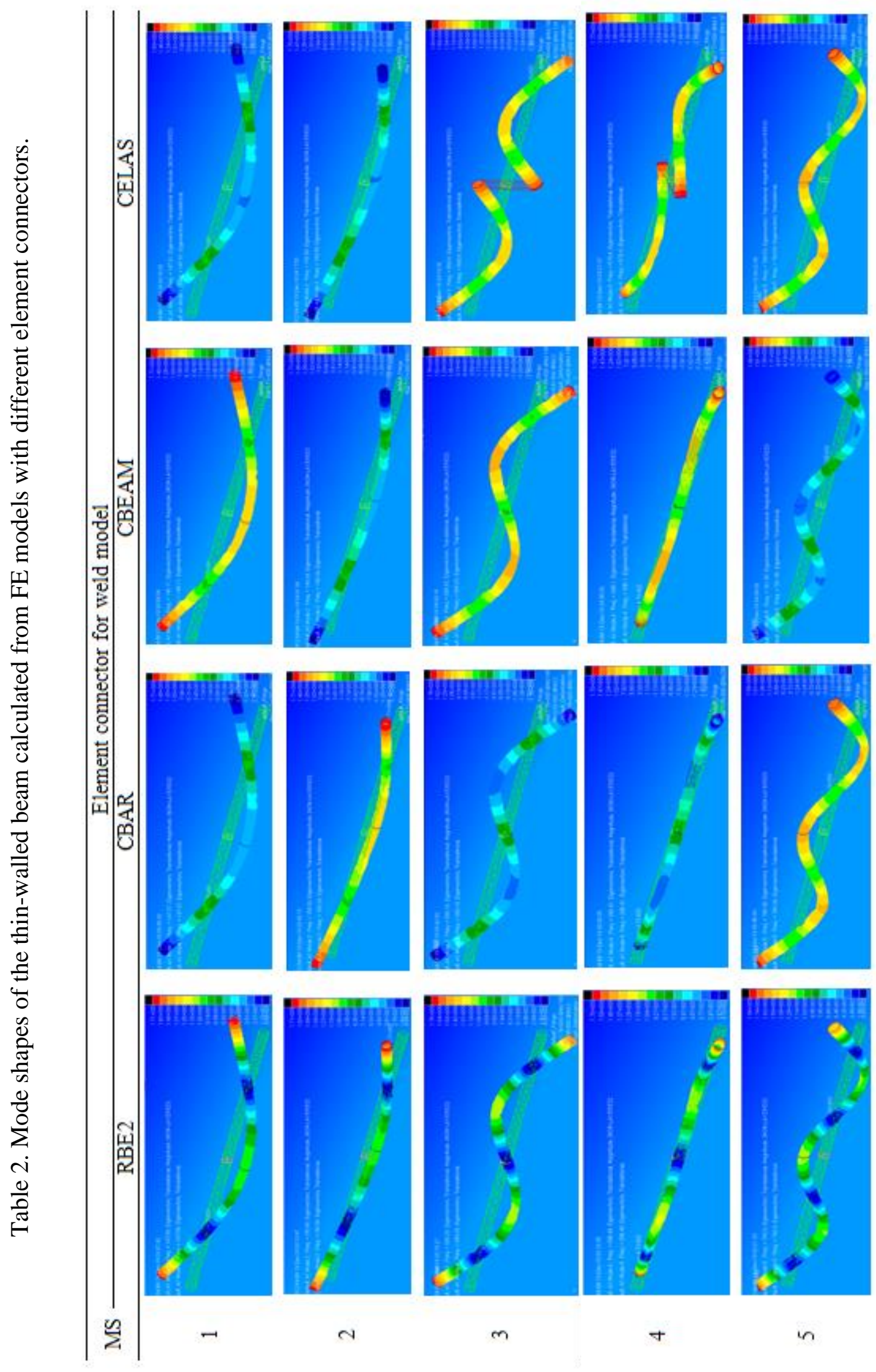




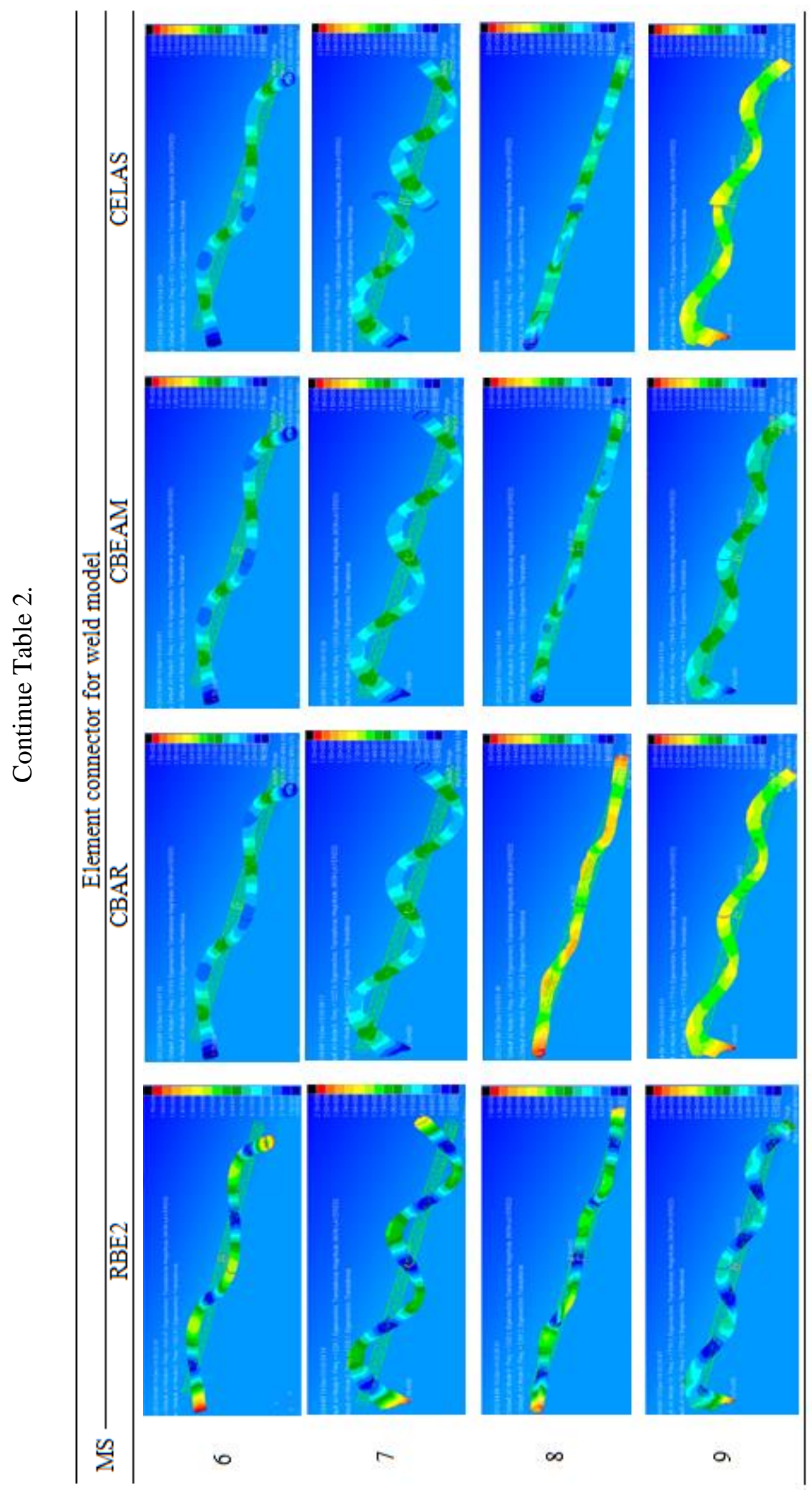


where $\mathbf{S}$ indicates the sensitivity matrix, $\mathbf{K}$ and $\mathbf{M}$ are the stiffness and mass matrices respectively, while $\phi, \lambda$ and $\theta$ represent eigenvector, eigenvalue and parameter respectively. Furthermore, $i$ indicate the $i$-th eigenvalue, and $j$ forthe $j$-th parameter.

After the iteration process was done, the sensitivity matrix coefficient was extracted from F06 file and tabulated in Table 3. The negative sign just indicated the vector direction and did not present the value of coefficient. From Table 3, it is clearly seen that Young Modulus and density are the most sensitive parameters, while Poisson's Ratio is slightly sensitive. In the other parameters, thickness does not show to be sensitive and therefore was excluded in the updating process. As a result, only Young Modulus, density and Poisson's Ratio have been selected for model updating process.

Table 3. Sensitivity matrix analysis coefficient analysed for four parameters.

\begin{tabular}{ccccc}
\hline $\begin{array}{c}\text { Natural Frequency } \\
(\text { NF })\end{array}$ & $\begin{array}{c}\text { Young Modulus } \\
(E)\end{array}$ & $\begin{array}{c}\text { Density } \\
(\rho)\end{array}$ & $\begin{array}{c}\text { Poisson's Ratio } \\
(v)\end{array}$ & Thickness \\
\hline NF 1 & 73.750 & -87.067 & -6.4327 & 0.61829 \\
NF 2 & 75.357 & -88.982 & -6.3456 & 0.64039 \\
NF 3 & 196.07 & -230.58 & -18.082 & 0.17748 \\
NF 4 & 199.80 & -234.95 & -19.424 & 0.15092 \\
NF 5 & 394.25 & -465.11 & -31.522 & 2.6830 \\
\hline
\end{tabular}

\section{Updating the Model}

Once the sensitive parameters have been identified, the model updating process was carried out to update the prediction data from FEA with their measured counterparts obtained in EMA. Regarding [8], an objective function based on residuals between the experimental modal data (e.g. natural frequencies, mode shape and etc.) and their predictions was set for minimization in the updating procedure. The procedure continues until convergence was accomplished when the difference between values of the objective function $G$ from consecutive iterations was sufficiently small. In this study, the objective function was constructed on the basis of eigenvalue residuals, given by Eq. (2).

$$
\boldsymbol{G}=\sum_{j=1}^{n}\left(\frac{\lambda_{j}}{\lambda_{j}^{\exp }}-1\right)^{2}
$$

where $\lambda_{j}^{e x p}$ was the $j$ th experimental eigenvalue and $\lambda_{j}$ was the $j$ th eigenvalue predicted by the FE model. It is important to note that Eq. (2) only held if the measured eigenvalue and its predicted counterpart were paired correctly, and therefore it was vital to ensure that the experimental and numerical data was related to the same mode [8]. The lower bound was set to be 0.85 while the upper bound was 1.15 for the updating process in this study. Since there were only three parameters selected in updating process, the desired eigenvalue involved in the process was set for the first four modes to avoid illconditioning as stated in the introduction. The computed model updating for the test has been tabled in Table 4 to be as the updated CBAR model. 


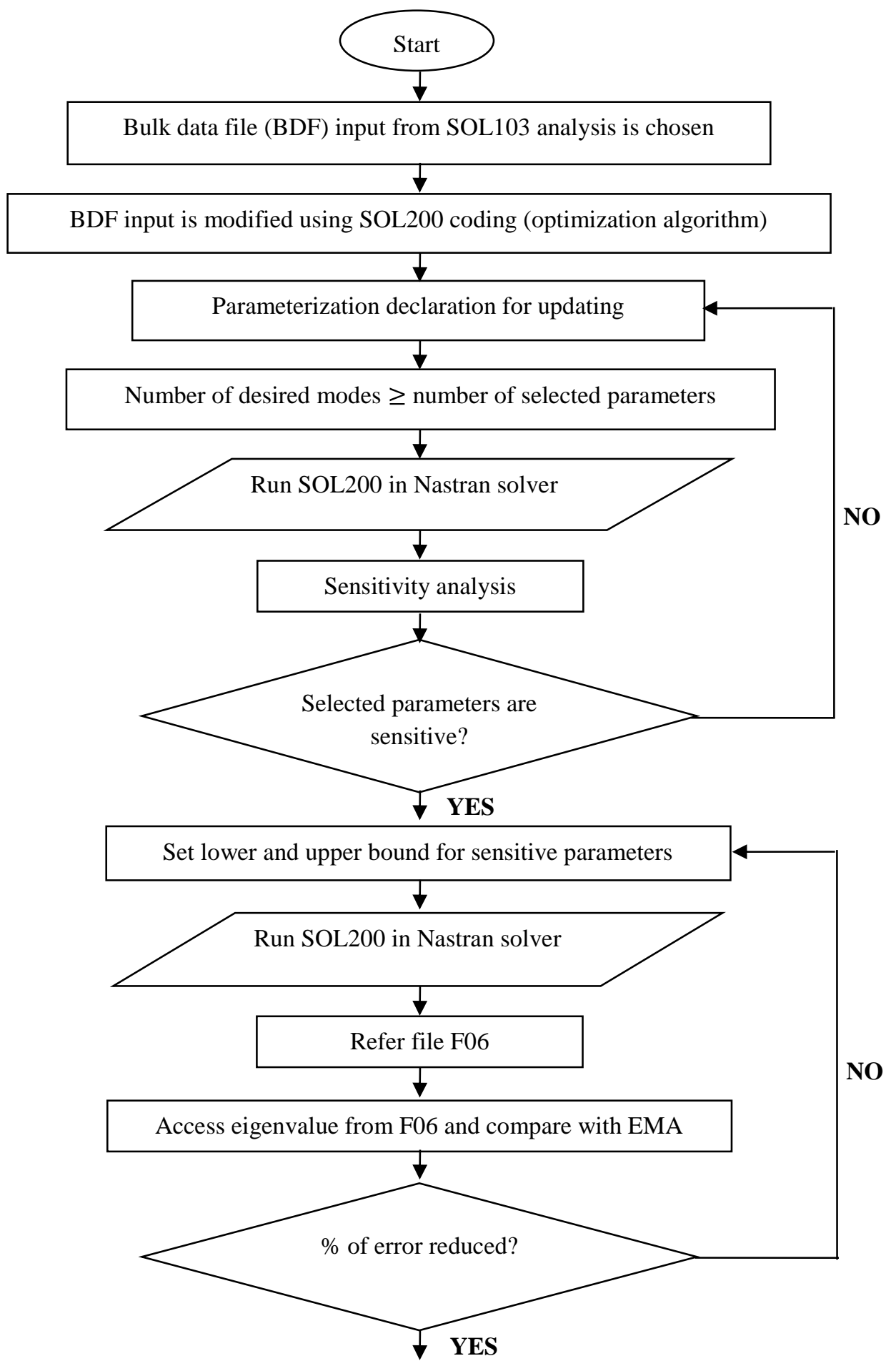

Check the updated parameters value based on suggested design variable in F06

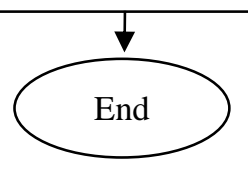

Figure 9. Flow process of FE model updating. 
Table 4. Correlation made between EMA and FEA (initial and updated CBAR model).

\begin{tabular}{cccccc}
\hline Mode & EMA & Initial CBAR & \% error & $\begin{array}{c}\text { Natural Frequency }(\mathrm{Hz}) \\
\text { CBdated }\end{array}$ & \% error \\
\hline 1 & 157 & 147.07 & 6.32 & 159.46 & 1.57 \\
2 & 159 & 150.33 & 5.45 & 162.96 & 2.49 \\
3 & 432 & 389.18 & 9.91 & 422.30 & 2.25 \\
4 & 439 & 396.41 & 9.70 & 430.30 & 1.98 \\
\hline \multicolumn{7}{l}{ Total average error } & & 7.85 & & 2.07 \\
\hline
\end{tabular}

For comprehensible output explanation from the updating process, comparisons were made between measured data with the original and updated predicted counterparts. In Table 4, it shows the percentage of error of CBAR model is managed to be reduced from $7.85 \%$ (original value) to $2.07 \%$ (updated value) compared to its experimental counterpart.

The new design variables computed in model updating can be accessed in F06 file and the new value of parameters is summarized in Table 5. The new values of design variables extracted from F06 file are 1.1500 for Young Modulus, 0.98878 for density and 0.85000 for Poisson's Ratio. The updated parameters value in Table 5 has supposedly been used as the new setting in the FE model parameterization since it has been verified to replicate the model as close as possible with the actual structure. As a result, the updated FE model is feasible to be used for further analysis such as stress analysis, static analysis and etc.

Table 5. Updated value of parameters based on design variable.

\begin{tabular}{|c|c|c|c|c|}
\hline Parameter & $\begin{array}{l}\text { Initial Value } \\
\text { (i) }\end{array}$ & $\begin{array}{l}\text { Updated Value } \\
\text { (u) }\end{array}$ & S.I. Unit & $\begin{array}{l}\text { Changes } \\
|(u-i) / i|\end{array}$ \\
\hline Young modulus $(E)$ & 190 & 219 & $\mathrm{GPa}$ & 0.15 \\
\hline Density $(\rho)$ & 7850 & 7762 & $\mathrm{~kg} / \mathrm{m}^{3}$ & 0.01 \\
\hline Poisson's ratio $(v)$ & 0.265 & 0.225 & - & 0.15 \\
\hline
\end{tabular}

\section{CONCLUSION}

The dynamic analysis was carried out in this study using numerical investigations of welded thin-walled beam through joint strategy approach. Four different types of element connectors which are RBE2, CBAR, CBEAM and CELAS existed in the FEA software was adopted as the weld joint model. The accuracy of numerical prediction results such as the natural frequency and the mode shape of each joint model have been correlated with its measured counterparts obtained from EMA. The best joint model with the lowest percentage of error and contains updating parameter has been selected for the FE model updating process to improve the correlation between prediction result and its experimental counterpart. As a result, the CBAR model showed precision to replicate the real structure and contains an updating parameter. Ahead of the updating process, the sensitivity analysis was done to identify only sensitive parameters to be used in the FE model updating. Only three parameters were found to be sensitive for updating the CBAR model with measured data. 
The updated CBAR model was accomplished to reduce the discrepancy between FEA and EMA with the reduction of percentage of error from its original value $7.85 \%$ to $2.07 \%$. In conclusion, the FE model updating process based on sensitivity analysis using predicted eigenvalue and experimental counterpart was capable in producing a reliable FE model. Hence, this systematic procedure to produce a feasible FE model of welded thin-walled beam can be extended for more complex structures such as exhaust structure, motorcycle frame, buggy car chassis and etc which use tubing as a main structure.

\section{ACKNOWLEDGEMENT}

The authors would like to greatly acknowledge the support by focus group of Advanced Structural Integrity of Vibration Research (ASiVR), Universiti Malaysia Pahang (UMP) for providing all the equipment used for this work. Last but not least, special thanks for Ministry of Education (MOE) for financial assistance support through Fundamental Research Grant Scheme (FRGS/1/2017/TK03/UMP/02-19) - RDU 170123and Jabatan Pendidikan Politeknik (JPP) for financial assistance and support with study leave through Hadiah Latihan Persekutuan (HLP) scholarship.

\section{REFERENCES}

[1] Živanović S, Pavic A, Reynolds P. Finite element modelling and updating of a lively footbridge: The complete process. Journal of Sound and Vibration. 2007;301:126-45.

[2] Zahari SN, Sani MSM, Ishak M. Finite element modelling and updating of friction stir welding (FSW) joint for vibration analysis. MATEC Web of Conferences. 2017;90.

[3] Abdullah NAZ, Sani MSM, Rahman MM, Zaman I. Correlation of numerical and experimental analysis for dynamic behaviour of a body-in-white (BIW) structure. MATEC Web of Conferences. 2017;90:01020.

[4] Shojaeifard MH, Ebrahimi-Nejad R, Kamarkhani S. Optimization of exhaust system hangers for reduction of vehicle cabin vibrations. International Journal of Automotive Engineering. 2017;7:2314-24.

[5] Rajadurai MS, Kavin R, Rejinjose, Prabhakaran, Rajeshraman. A system approach to dynamic characteristics of hanger rod in exhaust system. International Journal of Innovative Science, Engineering \& Technology. 2016;3:450-61.

[6] Pan GY, Cao DQ. Vibration characteristics analysis of exhaust system based on optimization of hanger position. 4th International Conference on Sustainable Energy and Enviromental Engineering (ICSEEE 2015)2016. p. 679-85.

[7] Gaonkar CD. Modal analysis of exhaust system to optimize mounting hanger location. International Journal of Engineering Research \& Technology (IJERT). 2015;4.

[8] Husain NA, Khodaparast HH, Snaylam A, James S, Dearden G, Ouyang H. Finiteelement modelling and updating of laser spot weld joints in a top-hat structure for dynamic analysis. Proceedings of the Institution of Mechanical Engineers, Part C: Journal of Mechanical Engineering Science. 2010;224:851-61.

[9] Rani MNA, Kasolang S, Othman MH, Yunus MA, Mirza WIIWI, Ouyang H. Finite element modelling and modal based updating for the dynamic behaviour of 
a laser spot welded structure. ICSV 2016-23rd International Congress on Sound and Vibration: From Ancient to Modern Acoustics. 2016:1-8.

[10] Izham MHN, Abdullah NAZ, Zahari SN, Sani MSM. Structural dynamic investigation of frame structure with bolted joints. MATEC Web of Conferences. 2017;90:01043.

[11] Schwarz BJ, Richardson MH. Experimental Modal Analysis. CSI Reliability Week, Orlando, FL. 1999.

[12] Carne TG, Stasiunas EC. Lessons learned in modal testing-part 3: Transient excitation for modal testing, more than just hammer impacts. Experimental Techniques. 2006;30:69-79.

[13] Abdullah NAZ, Sani MSM, Husain NA, Rahman MM, Zaman I. Dynamics properties of a Go-kart chassis structure and its prediction improvement using model updating approach. International Journal of Automotive and Mechanical Engineering. 2017;14:3887-97.

[14] Sani MSM, Nazri NA, Zahari SN, Abdullah NAZ, Priyandoko G. Dynamic study of bicycle frame structure. IOP Conference Series: Materials Science and Engineering: IOP Publishing; 2016. p. 012009.

[15] Mottershead JE, Link M, Friswell MI. The sensitivity method in finite element model updating: A tutorial. Mechanical systems and signal processing. 2011;25:2275-96.

[16] Husain NA, Khodaparast HH, Ouyang H. FE model updating of welded structures for identification of defects. International Journal of Vehicle Noise and Vibration. 2010;6:163-75.

[17] Husain NA, Snaylam A, Khodaparast HH, James S, Dearden G, Ouyang H. FE model updating for damage detection-application to a welded structure. Key Engineering Materials. 2009;413:393-400.

[18] Siemens. Element library reference. (C) 2014 Siemens Product Lifecycle Management Software Inc All Rights Reserved. 2014.

[19] Avitable P. Experimental modal analysis (a simple non-mathematical presentation). Annual Technical Meeting-Institute of Environmental Sciences and Technology. 2000;46:434-48.

[20] Ewins DJ. Modal testing: theory and practice: Research studies press Letchworth; 1984. 